\title{
An analytical equation for oil transport in nanopores of oil shale considering viscosity distribution
}

\author{
Fengrui Sun ${ }^{1,2,3} \cdot$ Yuedong $\mathrm{Yao}^{1,2,3} \cdot$ Xiangfang $\mathrm{Li}^{2,3} \cdot$ Guozhen $\mathrm{Li}^{3}$
}

Received: 15 October 2017 / Accepted: 10 May 2018 / Published online: 6 June 2018

(c) The Author(s) 2018

\begin{abstract}
Huge amount of works was done on modeling of gas transport in nanopores (both organic and inorganic) of shale formation. However, the study on oil transport behaviors is quite limited. Based on the study on water transport in carbon nanotubes, an analytical model is developed for oil transport in nanopores of shale formation. The new model takes the effect of oil-wall interaction on the oil viscosity in the adsorption region into consideration. Results show that: (1) the oil-wall interaction on oil viscosity in the adsorption region plays an important role in oil transport behaviors and cannot be neglected; (2) when the critical thickness is smaller than $1 \mathrm{~nm}$, the volume flux increases slowly with increasing contact angle; (3) when the critical thickness increases to $2 \mathrm{~nm}$, the volume flux increases rapidly to infinity when the contact angle is larger than $140^{\circ}$.
\end{abstract}

Keywords Shale oil $\cdot$ Nanopore $\cdot$ Oil transport $\cdot$ Viscosity variation $\cdot$ Critical thickness $\cdot$ Analytical model

\section{Introduction}

Great pressure is laid on the energy supply with the rapid rising population (Lee 2011; Sun et al. 2017a, b, c, d, e, f, g, h, i, j; Sheikholeslami et al. 2018a, b, c). Besides, the rapid depletion of conventional petroleum and natural gas resources aggravates the seriousness of the problem (Wang et al. 2018; Jia et al. 2018; Sun et al. 2018a, b, c, d, e, f, g, h, $\mathrm{i}, \mathrm{j}, \mathrm{k}, \mathrm{l})$. Fortunately, the geological reserves of unconventional oil and gas are extremely rich throughout the world, and the development of these resources has become a hot spot (Zhu et al. 2016). Shale oil reserves have been explored worldwide, and the US has seen a boom of oil shale development in recent years (Ribas et al. 2017; Soeder 2018; Alfarge

Fengrui Sun

13126682711@163.com

Yuedong Yao

yaoyuedong@163.com

1 State Key Laboratory of Petroleum Resources and Prospecting, China University of Petroleum - Beijing, Beijing 102249, People's Republic of China

2 College of Petroleum Engineering, China University of Petroleum - Beijing, Beijing 102249, People's Republic of China

3 China University of Petroleum - Beijing, Beijing 102249, People's Republic of China et al. 2018; Pang et al. 2018). However, the extremely poor connectivity of pores in shale and the ultralow permeability are the main characteristics of shale formation (Sheng et al. 2018; Shovkun et al. 2018). At present, the study on the oil transport mechanisms in nanopores of shale is quite limited (Lu et al. 2012; Falk et al. 2015; Bousige et al. 2016). The key physics of oil transport mechanisms in nanopores of shale are still held as mysteries (Cui et al. 2017).

Modern experimental means face challenges in isolating kerogen from the oil shale, and the critical knowledge about the physical and chemical properties of nanopores in shale is quite limited (Ibrahimov and Bissada 2010; Suleimenova et al. 2014). Therefore, molecular dynamics simulation (MDS) is always adopted in the preliminary study (Kondori et al. 2017; Rafati et al. 2018), and the kerogen is always described as graphene in the shale formation (Ambrose et al. 2012; Mosher et al. 2013; Harrison et al. 2014; Wang et al. 2015a, b, 2016a). Wang et al. (2016b) studied the profile of oil transport rate in nanopores of kerogen and the multilayer sticking phenomenon by adopting the MDS method. They found that there exists slip flow of oil in inorganic nanopores, which is different from that in kerogen, where some layers of oil are stuck to the nanopore wall. It has been pointed out that the flow enhancement, a ratio of oil transport rate in nanopores of shale to the calculated velocity by the Hagen-Poiseuille model, in organic nanopores of shale can be up to three orders of magnitude (Majumder et al. 
2005). The slip flow and apparent viscosity model is then developed to capture the physics of liquid transport in nanopores (Majumder et al. 2005; Chen et al. 2008). However, for the ideal graphite model, some unique characteristics of shale nanopores (e.g. wall roughness, radius change, hydrophilicity and hydrophobicity and tortuosity) cannot be considered (Schmatko et al. 2005; Bahrami et al. 2006; Joseph and Aluru 2008; Falk et al. 2010; Yang et al. 2015a, b; Gu et al. 2016; Guo et al. 2016; Joly et al. 2016). In fact, MDS is time consuming and cannot describe the surface properties well (Secchi et al. 2016). Besides, empirical equations cannot show the internal relationships among the physical parameters (e.g., the function relationship between sticking viscosity and wettability). The present study on the profile of oil velocity in nanopores is still at the early stage: the factors influencing the velocity profile is not well understood and whether the slip flow will always happen is still waited to be explored. What is worth to mention is that the present modeling methods of slip length and apparent viscosity are not the most appropriate for characterizing (Cui et al. 2017).

It has been pointed out that the viscosity of bulk oil in the center of the nanopores is equal to that of oil in macropores (Cui et al. 2017). As a result, adopting the predicted value of apparent viscosity may not reflect the actual profile of velocity. Besides, the present equations for characterizing the slip length may be physically unrealistic under some conditions (Myers 2011; Cui et al. 2017).

It has been pointed out that the wettability is the dominant factor influencing the liquid transport in nanopores under certain conditions (Neto et al. 2005; Thomas et al. 2009; Li et al. 2010; Ho et al. 2011; Botan et al. 2011; Majumder et al. 2011; Lee et al. 2012; Gruener et al. 2016; Wu et al. 2017; Cui et al. 2017). Mattia and Calabro (2012) presented a model for estimating the slip velocity of water flow in carbon nanotubes. Then, based on Mattia et al.'s work, a series of works were done on modeling of the flow enhancement at nanoscale (Park and Aluru 2007, 2010; Wei et al. 2011; Mattia et al. 2015). At present, in the theoretical study of water transport in nanotubes, the effect of surface diffusion, representing the water-wall interaction, adhesion work, wall roughness and the water-wall wettability were all taken into consideration, and some novel physics were discovered. However, present model shows a relatively poor fitness compared with experimental data (Zhang et al. 2002; Mashl et al. 2003; Kou et al. 2014, 2015; Cui et al. 2017). Ritos et al. (2014) conducted a verification test of the Mattia's model by simulating water transport in nanotubes of various wall materials. However, these previous works were almost focused on water transport in nanotube (mostly carbon nanotubes) (Thomas et al. 2008, 2010; Kannam et al. 2013; Muscatello et al. 2016; Wu et al. 2017). At present, the study on oil transport in nanopores of shale is quite limited.
It has been pointed out that the polar components in crude oil can be adsorbed on the surface of the nanopores and this part of oil is not easy to flow. Therefore, these polar components can be regarded as a part of the shale formation (Schwark et al. 1997; Qin et al. 2000; Pan et al. 2005; Cui et al. 2017). Cui et al. (2017) presented an analytical model for oil transport estimation in nanopores of oil shale with consideration of van der Waals adsorption (McGonigal et al. 1990), and compared the contributions of slip factor and adsorption factor on the flow enhancement. Besides, Cui et al. (2017) found the contribution of physical adsorption is negligible compared with slip flow, which is in agreement with water transport behaviors in carbon nanotubes (Kondratyuk and Yates 2007). For liquid flow through nanopores, the adsorption phenomenon is extremely important, which has an obvious influence on the flow enhancement (Wu et al. 2017). The adsorption region is the area where some layers of fluid are stuck to the nanopore walls and its physical parameters are significantly different from that of bulk liquid (Do and Do 2005; Severson and Snurr 2007; Sha et al. 2008). Riewchotisakul and Akkutlu (2016) presented a model for gas transport in nanopores of shale with consideration of physical adsorption. However, the physical parameters of gas are significantly different from that of liquid. Despite this, the studies on gas transport revealed the importance of physical adsorption on fluid transport at nanoscale (Akkutlu et al. 2012; Deng et al. 2014; Yang et al. 2015a, b; Wu et al. 2015). Zhang et al. (2017a) presented a model for predicting the volume flux of oil in nanopores of shale. However, their model failed to take the effect of oil-wall interaction on the viscosity of oil in the adsorption region into consideration.

In this paper, a modified model is developed for oil transport estimation in nanopores of shale considering spatial variation of oil viscosity. Then, sensitivity analysis is conducted based on the new equation.

\section{Model description}

The shale formation is rich in nanopores and nanoslits $(\mathrm{Li}$ et al. 2017; Feng et al. 2018a, b, c; Zhang et al. 2017a, b). A cross-section of a SEM image of a shale sample is shown in Fig. 1 below. It is observed that nanopores and nanoslits are distributed in both organic and inorganic materials of the shale formation.

A further study showed the nanopores of kerogen (the organic material) in the shale formation, as shown in Fig. 2 below. It is observed that nanopores (most of them are in cylindrical shape) are rich in abundance in the kerogen (Mohammed et al. 2017; Feng et al. 2018a, b). Therefore, in this paper, a cylindrical model is developed for oil transport in nanopores of shale formation. 

unsegmented and $\mathbf{b}$ segmented. Reproduced with permission from (Walls and Sinclair 2011; Song et al. 2018)
Fig. 1 A cross-section of a SEM image of a shale sample: a
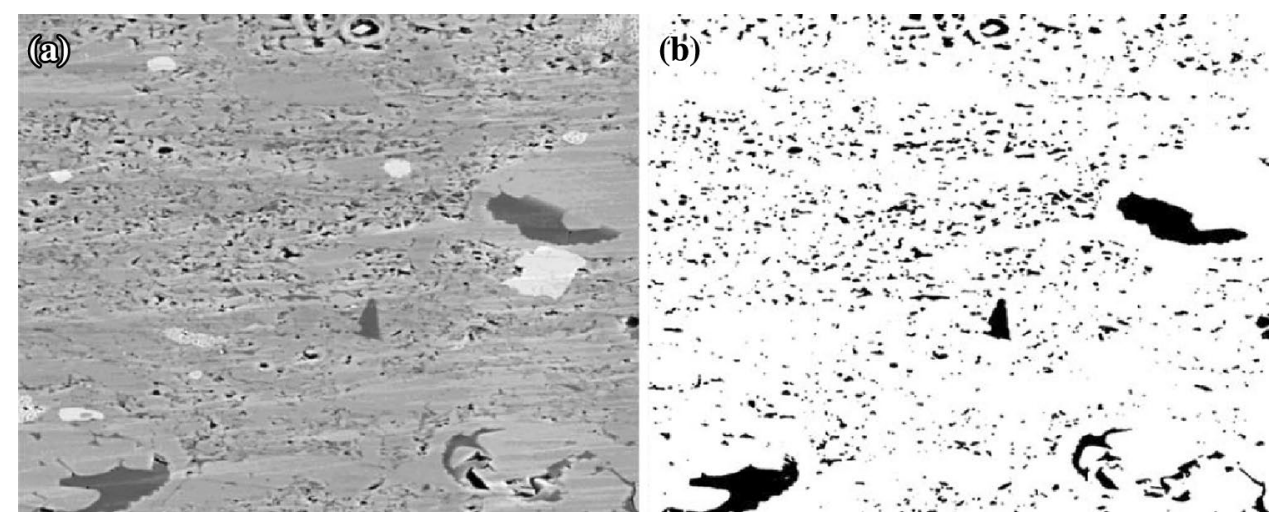

Fig. 2 Structure of nanopores in organic material of shale formation. Reproduced with permission from (Zeng et al. 2017)
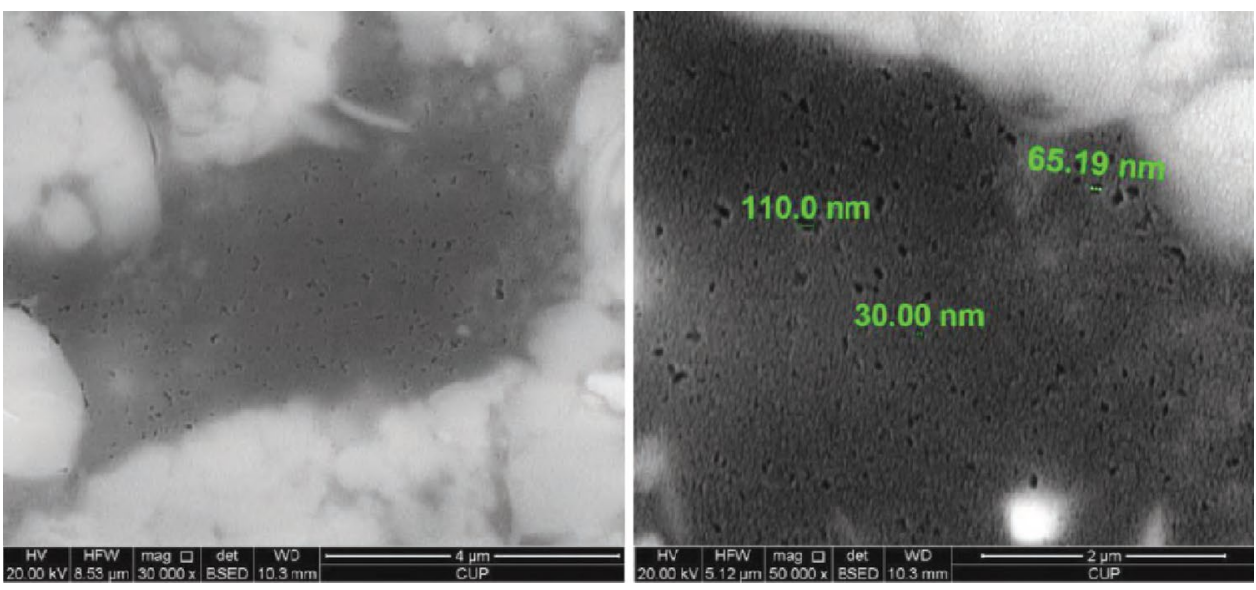

Based on both theoretical and MDS research, Zhang et al. (2017a) presented an analytical equation considering multiple mechanisms (e.g. physical adsorption, slip flow and physical and chemical properties of nanopore wall, etc.) of oil transport in nanopores of oil shale. The volume flux in their model is given below (Zhang et al. 2017a; Cui et al. 2017):

$q_{\mathrm{o}}=\xi_{\mathrm{C}}\left[\frac{\rho_{\mathrm{ads}}}{\rho_{\text {bulk }}}\left(1-\xi_{\text {ads }}\right)+\xi_{\text {ads }}\right] \frac{\pi R^{4} \Delta P}{8 \mu \mathrm{L}}$

$\xi_{\mathrm{C}}=1+\frac{8 \mu C_{1}}{R^{2}}$

$C_{1}=\frac{D_{\mathrm{S}} L}{W_{\mathrm{A}}}$

$\xi_{\mathrm{ads}}=\left(1-\frac{h}{R}\right)^{2}$

where $q_{o}$ denotes the volume flux of oil in nanopores of shale, $\mathrm{nm}^{3} / \mathrm{s} ; \xi_{\mathrm{C}}$ denotes the slip factor (Cui et al. 2017), dimensionless; $\rho_{\text {ads }}$ denotes the oil density in the adsorption region, $\mathrm{g} / \mathrm{nm}^{3} ; \rho_{\text {bulk }}$ denotes the density of bulk oil, $\mathrm{g} / \mathrm{nm}^{3}$; $\xi_{\text {ads }}$ denotes the factor (Cui et al. 2017), dimensionless; $R$ denotes the radius of the nanopore, nm; $P$ denotes the oil pressure, $\mathrm{mPa} ; \mu$ denotes the oil viscosity, $\mathrm{mPa} \cdot \mathrm{s} ; L$ denotes the length in the flow direction, nm; $C_{1}$ denotes the coefficient of slip velocity (Cui et al. 2017), dimensionless; $h$ denotes the thickness of the adsorption layer, nm.

As mentioned above, the oil-wall interaction plays an important role in oil properties, especially in the adsorption region. The oil viscosity in the adsorption region will increase or decrease according to the wettability of the nanopore wall. However, the oil viscosity in Eq. (1) is a constant, which leads to deviation to the calculated results. Thomas et al. (2008) proposed an analytical model for estimating effective water viscosity, which is a weighted average of water viscosity in the adsorption region and the bulk water, in nanotubes. In this paper, the model proposed by Thomas et al. is extended to describe the oil viscosity distribution in the nanopores of shale formation. According to Thomas et al.'s model, the effective viscosity of oil confined in the nanpores can be expressed as (Thomas et al. 2008):

$\mu(r)=\mu_{i} \frac{A_{i}(r)}{A_{t}(r)}+\mu_{\infty}\left[1-\frac{A_{i}(r)}{A_{t}(r)}\right]$

where $\mu(r)$ denotes the effective viscosity of oil confined in the nanpores of shale formation, $\mathrm{mP} \mathrm{s} ; \mu_{i}$ denotes the oil 
viscosity in the adsorption region, $\mathrm{mP} \mathrm{s} ; \mu_{\infty}$ denotes the viscosity of bulk oil, $\mathrm{mP} \mathrm{s} ; A_{i}(r)$ denotes the cross-sectional area of the adsorption region, $\mathrm{nm}^{2} ; A_{t}(r)$ denotes the cross section area of nanopore, $\mathrm{nm}^{2}$.

In this paper, it is assumed that Eq. (5), developed for water transport in carbon nanotubes, can also be used to calculate the oil viscosity in the nanopores of shale formation. This is because the lipophilicity or oleophobicity properties of an oil-wall system can lead to increase or decrease of oil viscosity in the surface region, which is similar to a water-wall system (Cui et al. 2017).

Wu et al. (2017) proposed an analytical equation for estimating water viscosity in the adsorption region based on MDS and experimental results. In this paper, we also assume that the equation developed for water viscosity calculation is effective in oil viscosity calculation. The empirical equation can be expressed as (Wu et al. 2017):

$\frac{\mu_{i}}{\mu_{\infty}}=-0.018 \theta_{w}+3.25$

where $\theta_{w}$ denotes the contact angle of a water droplet on the surface of a certain material, ${ }^{\circ}$.

Given the fact that the components of crude oil and the mineral compositions of shale sample are much more complicated than that of pure water and carbon, Eq. (6) is rewritten with two fitting parameters. The expression for oil transport in nanopores of shale or tight formation can be expressed as:

$\frac{\mu_{i}}{\mu_{\infty}}=-C_{2} \theta_{o}+C_{3}$

where $\theta_{o}$ denotes the contact angle of an oil-wall system, ${ }^{\circ}$.

Combining Eqs. (7) and (5), we can obtain:

$\mu(r)=\left(-C_{2} \theta_{o}+C_{3}\right) \mu_{\infty} \frac{A_{i}(r)}{A_{t}(r)}+\mu_{\infty}\left[1-\frac{A_{i}(r)}{A_{t}(r)}\right]$

Then, combining Eqs. (8) and (1), we can obtain:

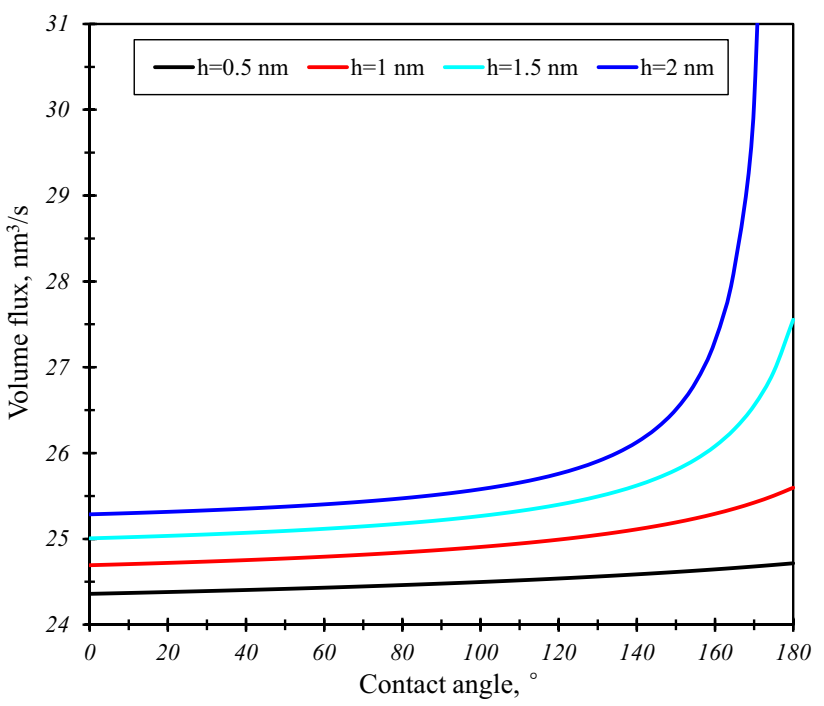

Fig. 3 The relationship between volume flux and contact angle under different critical thickness conditions

that the composition of crude oil varies significantly to each other, the curves under various critical thickness are shown for comparison.

It is observed from Fig. 3 that when the critical thickness is smaller than $1 \mathrm{~nm}$, the volume flux increases slowly with increasing contact angle. However, when the critical thickness increases to $2 \mathrm{~nm}$, the volume flux increases rapidly to infinity when the contact angle is larger than $140^{\circ}$. This means the effect of wettability on oil transport only make a contribution when the critical thickness is larger than $1.5 \mathrm{~nm}$.

\section{Conclusions}

In this paper, an improved model is developed with consideration of the effect of oil-wall interaction on the oil

$q_{o}=\xi_{C}\left[\frac{\rho_{a d s}}{\rho_{\text {bulk }}}\left(1-\xi_{\text {ads }}\right)+\xi_{a d s}\right] \frac{\pi R^{4} \Delta P}{8 L} \frac{1}{\left(-C_{2} \theta_{o}+C_{3}\right) \mu_{\infty} \frac{A_{i}(r)}{A_{t}(r)}+\mu_{\infty}\left[1-\frac{A_{i}(r)}{A_{t}(r)}\right]}$

Equation (9) is the analytical equation for estimating oil transport behaviors in nanopores of shale formation.

\section{Discussion}

In this section, the key findings of this work are discussed in detail. The relationship between the volume flux and contact angle is shown in Fig. 3 below. Given the fact viscosity in the adsorption region. Then, the effects of physical adsorption and wettability on the oil transport in nanopores are discussed in detail. Some meaningful conclusions are listed below:

(1) The oil-wall interaction on oil viscosity in the adsorption region plays an important role in oil transport behaviors and cannot be neglected. 
(2) When the critical thickness is smaller than $1 \mathrm{~nm}$, the volume flux increases slowly with increasing contact angle.

(3) When the critical thickness increases to $2 \mathrm{~nm}$, the volume flux increases rapidly to infinity when the contact angle is larger than $140^{\circ}$.

Following researchers are suggested to perform more studies on the physics in the surface region to obtain a satisfactory oil recovery efficiency of the oil shale reserves.

Acknowledgements The authors wish to thank the National Basic Research Program of China (2015CB250900), the Program for New Century Excellent Talents in University (Grant No. NCET-131030), the National Natural Science Foundation of China (Grant No. 40974055), the National Science and Technology Major Projects of China (2016ZX05039 and 2016ZX05042), the National Natural fund of China (51490654), and the Science Foundation of China University of Petroleum, Beijing (No. C201605).

Open Access This article is distributed under the terms of the Creative Commons Attribution 4.0 International License (http://creativeco mmons.org/licenses/by/4.0/), which permits unrestricted use, distribution, and reproduction in any medium, provided you give appropriate credit to the original author(s) and the source, provide a link to the Creative Commons license, and indicate if changes were made.

\section{References}

Akkutlu IY, Fathi E (2012) Multiscale gas transport in shales with local kerogen heterogeneities. SPE J 17:1002-1011

Alfarge D, Wei M, Bai B (2018) Data analysis for $\mathrm{CO}_{2}$-EOR in shaleoil reservoirs based on a laboratory database. J Petrol Sci Eng, 162:697-711

Ambrose RJ, Hartman RC, Diaz-campos M, Akkutlu IY, Sondergeld CH (2012) Shale gas-in-place calculations part I: new pore-scale considerations. SPE J 17:219-229

Bahrami M, Yovanovich MM, Culham JR (2006) Pressure drop of fully developed, laminar flow in rough microtubes. J Fluids Eng 128:632-637

Botan A, Rotenberg B, Marry V, Turq P, Noetinger B (2011) Hydrodynamics in clay nanopores. J Phys Chem C 115:16109-16115. https://doi.org/10.1021/jp204772c

Bousige C, Ghimbeu CM, Vix-Guterl C, Pomerantz AE, Suleimenova A, Vaughan G et al (2016) Realistic molecular model of kerogen's nanostructure. Nat Mater 15:576-582. https://doi. org/10.1038/nmat4541

Chen X, Cao G, Han A, Punyamurtula VK, Liu L, Culligan PJ et al (2008) Nanoscale fluid transport: size and rate effects. Nano Lett 8:2988-2992. https://doi.org/10.1021/nl802046b

Cui JF, Sang Q, Li YJ, Yin CB, Li YC, Dong MZ (2017) Liquid permeability of organic nanopores in shale: Calculation and analysis. Fuel 202:426-434

Deng J, Zhu W, Ma Q (2014) A new seepage model for shale gas reservoir and productivity analysis of fractured well. Fuel 124:232240. https://doi.org/10.1016/j.fuel.2014.02.001

Do DD, Do HD (2005) Adsorption of flexible n-alkane on graphitized thermal carbon black: analysis of adsorption isotherm by means of GCMC simulation. Chem Eng Sci 60:1977-1986. https://doi. org/10.1016/j.ces.2004.12.009
Falk K, Sedlmeier F, Joly L, Netz RR, Bocquet L (2010) Molecular origin of fast water transport in carbon nanotube membranes: superlubricity versus curvature dependent friction. Nano Lett 10:4067-4073. https://doi.org/10.1021/nl1021046

Falk K, Coasne B, Pellenq R, Ulm F, Bocquet L. Subcontinuum mass transport of condensed hydrocarbons in nanoporous media. Nat Commun 2015 https://doi.org/10.1038/ncomms7949

Feng D, Li XF, Wang XZ, Li J, Sun FR, Sun Z, Zhang T, Li PH, Chen Y, Zhang X (2018a) Water adsorption and its impact on the pore structure characteristics of shale clay. Appl Clay Sci 155:126-138

Feng D, Li XF, Wang XZ, Li J, Zhang X (2018b) Capillary filling under nanoconfinement: The relationship between effective viscosity and water-wall interactions. Int J Heat Mass Trans 118:900-910

Feng D, Li XF, Wang XZ, Li J, Zhang T, Sun Z, He MX, Liu Q, Qin JZ, Han S (2018c) Capillary filling of confined water in nanopores: Coupling the increased viscosity and slippage. Chem Eng Sci 186:228-239

Gruener S, Wallacher D, Greulich S, Busch M, Huber P (2016) Hydraulic transport across hydrophilic and hydrophobic nanopores: flow experiments with water and n-hexane. Phys Rev E 93:13102. https://doi.org/10.1103/PhysRevE.93.013102

Gu X, Mildner DFR, Cole DR, Rother G, Slingerland R, Brantley SL (2016) Quantification of organic porosity and water accessibility in Marcellus shale using neutron scattering. Energy Fuels 30:4438-4449. https://doi.org/10.1021/acs.energyfuels.5b02878

Guo L, Chen S, Robbins MO (2016) Slip boundary conditions over curved surfaces. Phys Rev E 93:13105. https://doi.org/10.1103/ PhysRevE.93.013105

Harrison A, Cracknell RF, Krueger-Venus J, Sarkisov L (2014) Branched versus linear alkane adsorption in carbonaceous slit pores. Adsorption 20:427-437. https://doi.org/10.1007/s1045 0-013-9589-1

Ho AT, Papavassiliou DV, Lee LL, Striolo A (2011) Liquid water can slip on a hydrophilic surface. Proc Natl Acad Sci USA 108:16170-16175. https://doi.org/10.1073/pnas.1105189108

Ibrahimov RA, Bissada KKA (2010) Comparative analysis and geological significance of kerogen isolated using open-system (palynological) versus chemically and volumetrically conservative closed-system methods. Org Geochem 41:800-811. https:// doi.org/10.1016/j.orggeochem.2010.05.006

Jia B, Tsau J-S, Barati B (2018) Role of molecular diffusion in heterogeneous, naturally fractured shale reservoirs during $\mathrm{CO}_{2}$ huff-npuff. J Petrol Sci Eng 164:31-42

Joly L, Tocci G, Merabia S, Michaelides A (2016) Strong coupling between nanofluidic transport and interfacial chemistry: how defect reactivity controls liquid-solid friction through hydrogen bonding. J Phys Chem Lett 7:1381-1386. https://doi. org/10.1021/acs.jpclett.6b00280

Joseph S, Aluru NR (2008) Why are carbon nanotubes fast transporters of water? Nano Lett 8:452-458

Kannam SK, Todd BD, Hansen JS, Daivis PJ (2013) How fast does water flow in carbon nanotubes? J Chem Phys 138:94701. https ://doi.org/10.1063/1.4793396

Kondori J, Zendehboudi S, Hossain ME (2017) A review on simulation of methane production from gas hydrate reservoirs: Molecular dynamics prospective. J Petrol Sci Eng 159:754-772

Kondratyuk P, Yates JT (2007) Molecular views of physical adsorption inside and outside of single-wall carbon nanotubes. Acc Chem Res 40:995-1004. https://doi.org/10.1021/ar700013c

Kou J, Lu H, Wu F, Fan J, Yao J (2014) Electricity resonance-induced fast transport of water through nanochannels. Nano Lett 14:4931-4936

Kou J, Yao J, Lu H, Zhang B, Li A, Sun Z et al (2015) Electromanipulating water flow in nanochannels. Angew Chem 127:2381-2385. https://doi.org/10.1002/ange.201408633

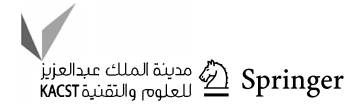


Lee R (2011) The outlook for population growth. Science 333:569-573 Lee KP, Leese H, Mattia D (2012) Water flow enhancement in hydrophilic nanochannels. Nanoscale 4:2621-2627. https://doi. org/10.1039/b000000x

Li Y, Xu J, Li D (2010) Molecular dynamics simulation of nanoscale liquid flows. Microfluid Nanofluid 9:1011-1031. https://doi. org/10.1007/s10404-010-0612-5

Li J, Li K, Wu D, Feng T, Zhang Y, Zhang (2017) Thickness and stability of water film confined inside nanoslits and nanocapillaries of shale and clay. Int J Coal Geol 179:253-268

Lu S, Huang W, Chen F, Li J, Wang M, Xue H et al (2012) Classification and evaluation criteria of shale oil and gas resources: discussion and application. Pet Explor Dev 39:268-276. https ://doi.org/10.1016/S1876-3804(12)60042-1

Majumder M, Chopra N, Andrews R, Hinds BJ (2005) Nanoscale hydrodynamics: enhanced flow in carbon nanotubes. Nature 438:44-44. https://doi.org/10.1038/43843a.

Majumder M, Chopra N, Hinds BJ (2011) Mass transport through carbon nanotube membranes in three different regimes: ionic diffusion and gas and liquid flow. ACS Nano 5:3867-3877

Mashl RJ, Joseph S, Aluru NR, Jakobsson E (2003) Anomalously immobilized water: a new water phase induced by confinement in nanotubes. Nano Lett 3:589-592. https://doi.org/10.1021/ n10340226

Mattia D, Calabro F (2012) Explaining high flow rate of water in carbon nanotubes via solid-liquid molecular interactions. Microfluid Nanofluid 13:125-130. https://doi.org/10.1007/ s10404-012-0949-z

Mattia D, Leese H, Lee KP (2015) Carbon nanotube membranes: from flow enhancement to permeability. J Membr Sci 475:266272. https://doi.org/10.1016/j.memsci.2014.10.035

McGonigal GC, Bernhardt RH, Thomson DJ (1990) Imaging alkane layers at the liquid/graphite interface with the scanning tunneling microscope. Appl Phys Lett 57:28-30. https://doi. org/10.1063/1.104234

Mosher K, He J, Liu Y, Rupp E, Wilcox J (2013) Molecular simulation of methane adsorption in micro- and mesoporous carbons with applications to coal and gas shale systems. Int J Coal Geol 109-110:36-44. https://doi.org/10.1016/j.coal.2013.01.001

Muscatello J, Jaeger F, Matar OK, Mu EA (2016) Optimizing water transport through graphene-based membranes: insights from nonequilibrium molecular dynamics. ACS Appl Mater Interfaces 8:12330-12336. https://doi.org/10.1021/acsami.5b12112

Myers TG (2011) Why are slip lengths so large in carbon nanotubes? Microfluid Nanofluid 10:1141-1145. https://doi.org/10.1007/ s10404-010-0752-7

Neto C, Evans DR, Bonaccurso E, Butt H-J, Craig VSJ (2005) Boundary slip in Newtonian liquids: a review of experimental studies. Reports Prog Phys 68:2859-2897. https://doi. org/10.1088/0034-4885/68/12/R05

Pan C, Feng J, Tian Y, Yu L, Luo X, Sheng G et al (2005) Interaction of oil components and clay minerals in reservoir sandstones. Org Geochem 36:633-654. https://doi.org/10.1016/j.orgge ochem.2004.10.013

Pang H, Pang XQ, Li D Xu Z (2018) Factors impacting on oil retention in lacustrine shale: Permian Lucaogou Formation in Jimusaer Depression, Junggar Basin. J Petrol Sci Eng 163:79-90

Park JH, Aluru NR (2007) Surface diffusion of n-alkanes: mechanism and anomalous behavior. Chem Phys Lett 447:310-315. https:// doi.org/10.1016/j.cplett.2007.09.047

Park JH, Aluru NR (2010) Ordering-induced fast diffusion of nanoscale water film on graphene. J Phys Chem C 114:2595-2599. https:// doi.org/10.1021/jp907512z
Qin X, Wang P, Sepehrnoori K, Pope GA (2000) Modeling asphaltene precipitation in reservoir simulation. Ind Eng Chem Res 39:2644-2654

Rafati R, Smith SR, Haddad AS, Novara R (2018) Effect of nanoparticles on the modifications of drilling fluids properties: a review of recent advances. J Petrol Sci Eng, 161:61-76

Ribas L, Herinque K (2017) José Manoel dos Reis Neto, Almério Barros França. Porto Alegre. The behavior of Irati oil shale before and after the pyrolysis process. J Petrol Sci Eng 152:156-164

Riewchotisakul S, Akkutlu IY (2016) Adsorption enhanced transport of hydrocarbon in organic nanopores. SPE J 21:28-30

Ritos K, Mattia D, Calabrò F, Reese JM (2014) Flow enhancement in nanotubes of different materials and lengths. J Chem Phys 140:14702. https://doi.org/10.1063/1.4846300

Sayed MA, Al-Muntasheri GA, Liang F (2017) Development of shale reservoirs: Knowledge gained from developments in North America. J Petrol Sci Eng 157:164-186

Schmatko T, Hervet H, Leger L (2005) Friction and slip at simple fluid-solid interfaces: the roles of the molecular shape and the solid-liquid interaction. Phys Rev Lett 94:244501. https://doi. org/10.1103/PhysRevLett.94.244501

Schwark L, Stoddart D, Keuser C, Spitthoff B, Leythaeuser D (1997) A novel sequential extraction system for whole core plug extraction in a solvent flow-through cell-Application to extraction of residual petroleum from an intact pore system in secondary migration studies. Org Geochem 26:19-31. https://doi.org/10.1016/S0146 $-6380(96) 00163-5$

Secchi E, Marbach S, Niguès A, Stein D, Siria A, Bocquet L (2016) Massive radiusdependent flow slippage in carbon nanotubes. Nature 537:210-213. https://doi.org/10.1038/nature19315

Severson BL, Snurr RQ (2007) Monte Carlo simulation of n-alkane adsorption isotherms in carbon slit pores. J Chem Phys 126:134708. https://doi.org/10.1063/1.2713097

Sha M, Zhang F, Wu G, Fang H, Wang C, Chen S et al (2008) Ordering layers of [bmim] [P F6] ionic liquid on graphite surfaces: molecular dynamics simulation. J Chem Phys 128:134504. https ://doi.org/10.1063/1.2898497

Sheikholeslami M (2018a) Numerical simulation for solidification in a LHTESS by means of Nano-enhanced PCM. J Taiwan Inst Chem Eng 86:25-41

Sheikholeslami M (2018b) CuO-water nanofluid flow due to magnetic field inside a porous media considering Brownian motion. J Mol Liq 249:921-929

Sheikholeslami M (2018c) Numerical modeling of Nano enhanced PCM solidification in an enclosure with metallic fin. J Mol Liq 259:424-438

Sheng M, Li G, Sutula D, Tian S, Bordas SPA (2018) XFEM modeling of multistage hydraulic fracturing in anisotropic shale formations. J Petrol Sci Eng 162:801-812

Shovkun I, Espinoza DN (2018) Geomechanical implications of dissolution of mineralized natural fractures in shale formations. J Petrol Sci Eng 160:555-564

Soeder DJ (2018) The successful development of gas and oil resources from shales in North America. J Petrol Sci Eng 163:399-420

Song W, Yao J, Ma J et al (2018) Numerical simulation of multiphase flow in nanoporous organic matter with application to coal and gas shale systems. Water Res Res 54:1077-1092

Suleimenova A, Bake KD, Ozkan A, Valenza JJ, Kleinberg RL, Burnham AK et al (2014) Acid demineralization with critical point drying: a method for kerogen isolation that preserves microstructure. Fuel 135:492-497. https://doi.org/10.1016/j. fuel.2014.07.005

Sun FR, Yao YD, Li XF (2017a) Effect analysis of non-condensable gases on superheated steam flow in vertical single-tubing steam injection pipes based on the real gas equation of state and the 
transient heat transfer model in formation. J Petrol Explor Prod Technol. https://doi.org/10.1007/s13202-017-0419-y

Sun FR, Yao YD, Li XF (2017b) Effect of gaseous $\mathrm{CO}_{2}$ on superheated steam flow in wells. Eng Sci Technol Int J 20(6):1579-1585

Sun FR, Yao YD, Li XF (2017c) Numerical simulation of superheated steam flow in dual-tubing wells. J Petrol Explor Prod Technol. https://doi.org/10.1007/s13202-017-0390-7

Sun FR, Yao YD, Li XF, Li H, Chen G, Sun Z (2017d) A numerical study on the non-isothermal flow characteristics of superheated steam in ground pipelines and vertical wellbores. J Petrol Sci Eng 159:68-75

Sun FR, Yao YD, Li XF, Tian J, Zhu GJ, Chen Z (2017e) The flow and heat transfer characteristics of superheated steam in concentric dual-tubing wells. Int J Heat Mass Transf 115:1099-1108

Sun FR, Yao YD, Li XF, Yu PL, Ding GY, Zou M (2017f) The flow and heat transfer characteristics of superheated steam in offshore wells and analysis of superheated steam performance. Comput Chem Eng 100:80-93

Sun FR, Yao YD, Li XF, Zhao L (2017g) Type curve analysis of superheated steam flow in offshore horizontal wells. Int J Heat Mass Transf 113:850-860

Sun FR, Yao YD, Li XF, Yu PL, Zhao L, Zhang Y (2017h) A numerical approach for obtaining type curves of superheated multi-component thermal fluid flow in concentric dual-tubing wells. Int J Heat Mass Transf 111:41-53

Sun FR, Yao YD, Chen MQ, Li XF, Zhao L, Meng Y, Sun Z, Zhang T, Feng D (2017i) Performance analysis of superheated steam injection for heavy oil recovery and modeling of wellbore heat efficiency. Energy 125:795-804

Sun FR, Yao YD, Li XF, Zhao L, Ding GY, Zhang XJ (2017j) The mass and heat transfer characteristics of superheated steam coupled with non-condensing gases in perforated horizontal wellbores. J Petrol Sci Eng 156:460-467

Sun FR, Yao YD, Li GZ, Li XF, Chen MQ, Chen G, Zhang T (2018a) Analysis of superheated steam performance in offshore concentric dual-tubing wells. J Petrol Sci Eng 166:984-999

Sun FR, Yao YD, Li XF (2018b) The heat and mass transfer characteristics of superheated steam in horizontal wells with toe-point injection technique. J Petrol Explor Prod Technol https://doi. org/10.1007/s13202-017-0407-2

Sun FR, Yao YD, Li GZ, Li XF, Zhang T, Lu CG, Liu WY (2018c) An improved two-phase model for saturated steam flow in multipoint injection horizontal wells under steady-state injection condition. J Petrol Sci Eng 167:844-856

Sun FR, Yao YD, Li XF, Li GZ (2018d) A brief communication on the effect of seawater on water flow in offshore wells at supercritical state. J Petrol Explor Prod Technol https://doi.org/10.1007/ s13202-018-0456-1

Sun FR, Yao YD, Li GZ, Li XF, Lu CG, Chen ZL (2018e) A model for predicting thermophysical properties of water at supercritical state in offshore CDTW. Measurement 124:241-251

Sun FR, Yao YD, Li XF, Li GZ, Han S, Liu Q, Liu WY (2018f) Type curve analysis of multi-phase flow of multi-component thermal fluid in toe-point injection horizontal wells considering phase change. J Petrol Sci Eng 165:557-566

Sun FR, Yao YD, Li XF, Li GZ, Miao YN, Han S, Chen ZL (2018g) Flow Simulation of the Mixture System of Supercritical $\mathrm{CO}_{2} \&$ Superheated Steam in Toe-point Injection Horizontal wellbores. J Petrol Sci Eng 163:199-210

Sun FR, Yao YD, Li XF, Li GZ, Huang L, Liu H, Chen ZL, Liu Q, Liu WY, Cao M, Han S (2018h) Exploitation of heavy oil by supercritical $\mathrm{CO}_{2}$ : effect analysis of supercritical $\mathrm{CO}_{2}$ on $\mathrm{H}_{2} \mathrm{O}$ at superheated state in integral joint tubing and annuli. Greenhouse Gases. https://doi.org/10.1002/ghg.1764

Sun FR, Yao YD, Li XF, Li GZ, Sun Z (2018i) A numerical model for predicting distributions of pressure and temperature of superheated steam in multi-point injection horizontal wells. Int J Heat Mass Transf 121:282-289

Sun FR, Yao YD, Li XF, Li GZ, Chen ZL, Chang YC, Cao M, Han S, Lv CH, Feng D, Sun Z (2018j) Effect of flowing seawater on supercritical $\mathrm{CO}_{2}$ - superheated water mixture flow in an offshore oil well considering the distribution of heat generated by the work of friction. J Petrol Sci Eng 162:460-468

Sun FR, Yao YD, Li XF (2018k) The heat and mass transfer characteristics of superheated steam coupled with non-condensing gases in horizontal wells with multi-point injection technique. Energy 143:995-1005

Sun FR, Yao YD, Li XF, Li GZ, Liu Q, Han S, Zhou YJ (20181) Effect of friction work on key parameters of steam at different state in toe-point injection horizontal wellbores. J Petrol Sci Eng 164:655-662

Thomas JA, Mcgaughey AJH (2008) Reassessing fast water transport through carbon nanotubes. Nano Lett 8:2788-2793. https://doi. org/10.1021/nl801361

Thomas JA, McGaughey AJH (2009) Water flow in carbon nanotubes: transition to subcontinuum transport. Phys Rev Lett 102:184502. https://doi.org/10.1103/PhysRevLett.102.184502

Thomas JA, McGaughey AJH, Kuter-Arnebeck O (2010) Pressuredriven water flow through carbon nanotubes: Insights from molecular dynamics simulation. Int J Therm Sci 49:281-289. https://doi.org/10.1016/j.ijthermalsci.2009.07.008

Walls JD, Sinclair SW (2011) Eagle Ford shale reservoir properties from digital rock physics. First Break 29(6):97-101

Wang S, Feng Q, Javadpour F, Xia T, Li Z (2015a) Oil adsorption in shale nanopores and its effect on recoverable oil-inplace. Int J Coal Geol 147-148:9-24. https://doi.org/10.1016/j. coal.2015.06.002

Wang S, Feng Q, Zha M, Lu S, Qin Y, Xia T et al (2015b) Molecular dynamics simulation of liquid alkane occurrence state in pores and slits of shale organic matter. Pet Explor Dev 42:844-851. https://doi.org/10.11698/PED.2015.06.10

Wang S, Javadpour F, Feng Q (2016a) Fast mass transport of oil and supercritical carbon dioxide through organic nanopores in shale. Fuel 181:741-758. https://doi.org/10.1016/j. fuel.2016.05.057

Wang S, Javadpour F, Feng Q (2016b) Molecular dynamics simulations of oil transport through inorganic nanopores in shale. Fuel 171:74-86. https://doi.org/10.1016/j.fuel.2015.12.071

Wang BY, Qin Y, Shen J, Zhang QS, Wang G (2018) Pore structure characteristics of low- and medium-rank coals and their differential adsorption and desorption effects. J Petrol Sci Eng 165:1-12

Wei MJ, Zhou J, Lu X, Zhu Y, Liu W, Lu L et al (2011) Diffusion of water molecules confined in slits of rutile TiO2(lllll 10 ) and graphite(0 00 1). Fluid Phase Equilib 302:316-320. https://doi. org/10.1016/j.fluid.2010.09.044

Wu K, Li X, Wang C, Yu W, Chen Z (2015) Model for surface diffusion of adsorbed gas in nanopores of shale gas reservoirs. Ind Eng Chem Res 54:3225-3236. https://doi.org/10.1021/ie504030v

Wu K, Chen Z, Li J, Li X, Xu J, Dong X (2017) Wettability effect on nanoconfined water flow. Proc Natl Acad Sci USA 114(13):3358-3363

Yang S, Liang M, Yu B, Zou M (2015a) Permeability model for fractal porous media with rough surfaces. Microfluid Nanofluid 18:1085-1093. https://doi.org/10.1007/s10404-014-1500-1

Yang T, Li X, Zhang D (2015b) Quantitative dynamic analysis of gas desorption contribution to production in shale gas reservoirs. $\mathbf{J}$ Unconv Oil Gas Resou 9:18-30. https://doi.org/10.1016/j.juogr .2014.11.003

Zeng Y, Ning ZF, Qi RR, Huang L (2017) LV C. Simulation of transport of shale gas through the nanopores of shales. Petrol Sci Bull 01:64-75. https://doi.org/10.3969/j.issn.2096-1693.2017.01.007

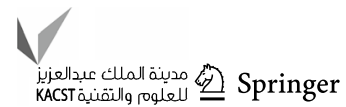


Zhang Q, Zheng J, Shevade A, Zhang L, Gehrke SH, Heffelfinger GS et al (2002) Transport diffusion of liquid water and methanol through membranes. J Chem Phys 117:808-818. https://doi. org/10.1063/1.1483297

Zhang T, Li XF, Li J, Feng D, Li PH, Zhang ZH, Chen Y, Wang S (2017a) Numerical investigation of the well shut-in and fracture uncertainty on fluid-loss and production performance in gasshale reservoirs. J Nat Gas Sci Eng 46:421-435

Zhang T, Dong M, Li Y. A fractal permeability model for shale oil reservoir. Earth Environ Sci 108 (2017b) 032083
Zhu G, Yao J, Sun H, Zhang M, Xie M, Sun Z et al (2016) The numerical simulation of thermal recovery based on hydraulic fracture heating technology in shale gas reservoir. J Nat Gas Sci Eng 28:305-316. https://doi.org/10.1016/j.jngse.2015.11.051

Publisher's Note Springer Nature remains neutral with regard to jurisdictional claims in published maps and institutional affiliations. 